\title{
Linear Programming as a Tool for Water Resources Management
}

\author{
Obi Lawrence E. (Ph.D) \\ Department of Civil Engineering, Imo State University, P.M.B. 2000, Owerri, Imo State, Nigeria
}

*Corresponding Author: Obi Lawrence E. Department of Civil Engineering, Imo State University P.M.B. 2000, Owerri, Imo State, Nigeria

\begin{abstract}
Water resources management needs more numerical techniques which can be utilized in its analysis of concepts and principles. Linear programming has come to occupy a unique position in the numerical analysis of issues that demand high degree of precision and accuracy. This work has succeeded in exposing the uniqueness of linear programming in water resources utilizations, modeling and optimization through the maximization of benefits, gains and profits and the minimization of losses, expenditure and labour. This research has explicitly thrown immense light on the various methods of linear programming and how they can be applied in the multifarious areas of water resources engineering.
\end{abstract}

\section{INTRODUCTION}

The origin of linear programming has been traced to the period of the Second World War which prevailed between 1939 and 1945. The war required a lot of logistics in view of its complexity and grandiose nature in terms of materials management, equipment, personnel and area of coverage. This led to innovative efforts of the protagonist war nation of England in studying the problems of the war particularly the problems of armed forces, civil defence, air force and their associated logistics. The efforts made in these studies gave birth to the concept of linear programming. Further to that, during the $2^{\text {nd }}$ World War, Marshall K. Wood worked on the allocation of the resources for the United States of America, while George B. Dantzig- member of the U.S Air Force devised a method of allocating resources through the minimization and maximization of the desire object of the problem in 1947 (Sharma, 2009). Globally, linear programming has become the most popular mathematical technique applied in the allocation of scarce resources

\section{ConcePt OF Linear Programming ModelS}

Linear programming can be defined as planning to maximize profits, benefits, or minimize loss and wastes in any given system with the variables having exponent value of one. The term programming means the planning, that can lead to the maximization and minimization of the goals and objectives while the linear denotes that the power of the process or equation variable of one. Linear programming comes in forms of mathematical formulations of processes and as such are often called linear programming problems or optimization problems. Linear programming is also a mathematical technique for determining a way to achieve the best outcome in a given mathematical expression with some set of inequalities whose terms, maintain linear relationships, (Gupta et al, 2010).

Stroud (2003), defined linear programming as a method of solving an optimization problem when the objective function is a linear and the constraints are linear equations or linear inequalities. An optimization problem requires the determination of the optimal maximum or minimum value of a given function called the objective function (goal) subject to a set of stated restrictions placed on the variables involved.

In order to develop and apply specific operations, research techniques are used to determine the optimal choice, among other several courses of action, including the evaluation of specific numerical values (if required), there is also need to construct (or formulate) a mathematical model. The term formulation refers to the process of converting the verbal descriptions and numerical data into mathematical expressions, which represents the relationships among relevant decision variables (or factors), objective and restrictions (constraints), on the use of resources such as labour, material, machine, time, warehouse space, capital, energy etc., to several competing activities, such as products, 
services jobs, new equipment, projects etc., on the basis of a given criterion of optimality (George et al, 2000).. The phrase scarce resources refer to resources that are not available in infinite quantity. The criterion of optimality is generally either performance, return on investment, profit, utility, time, distance or the like.

The usefulness of this technique is enhanced by the availability of user-friendly computer software such as STORM, TORA, QSB, LINDO etc. However, there is no computer software for building an LP model. Model building is an art that improves through experience and practice. (Sharma, 2009). In any linear programming problem, a measurable objective or criterion of effectiveness must be identified. This type of objectives can usually be quantified and become the objective function of the problem. Assumption of linearity implies that it is a linear objective function.

The objective function is nothing more than a mathematical expression that describes the manner in which profit accumulates as a function or the loss reduces as a function of the number of different services or products produced. The maximization or minimization of any linear function does not make sense without imposing some sort of additional constraints. The technical specifications of a linear programming problem and how they relate to fixed resource capacities are expressed by a set of structural constraints. The assumption of linearity implies that such a set is linear. Since any production programming must be such that it cannot demand resource in excess of the given capacities, the linear structural constraints for linear programming problems, must be expressed as inequalities or the "less than or equal to" or " greater than or equal to" type.

A linear programming model consists of

* An objectives function to be maximized or minimized

* A set of constraints

* Decision variables

*Linearity among all constraint relationships and the objective function

\subsection{Formulation of Linear Programming Models}

Linear programming is a mathematical method in operations research which requires a logical, systematic approach in problem solving and the steps involved in such formulation include:

- Observation

- Definition of the problem

- Model construction

- Model solution

- Implementation

(Taylor, 1986).

\section{- Observation}

The system needs to be studied thoroughly to understand its modus operandi, the components, internal and external factors that influence its operations and products. The problem to be solved with regards to the system must be identified. The problem may be identified by a skilled operator of the system or by the key management staff that determine the corporate goals.

\section{- Problem Definition}

At this stage, the factors and variables identified must be properly defined with boundaries and limits. The corporate goal should be defined as the objective function while the limits and boundaries are considered as constraints.

\section{- Model Construction}

The defined factors and variables can be translated into mathematical expressions and inequalities. The mathematical expression represent the objective function while the inequalities stand for the constraints. The terms in the equations must bear functional relationships with each other. The 
variables in the expressions and inequalities are symbols that represent time levels of activities in the system. The corporate goal of the system represents the objective functions expressed in terms of the decision variables. The objective function is subjected to the minimization and maximization processes. For instance, when the objective function is to reduce the cost of input resources, labour, loss, waste etc the minimization process is applied while when the target is to enhance profit, benefits, production output, the maximization process comes into play. The constraints are composed with the decision variable with relationship which represents the boundaries of limitation of the system within the operating environment. The LP model is best built by integrating appropriate relationships (equations/expressions) from the physical problems with complete boundary conditions and well defined variables (Obi, 2013).

\section{- Model Solution}

The composition of the model equations demands that the equations be solved. The composed models expressions and inequalities are solved using the appropriate operations research technique. The result of the solutions is the determination of the values for the decision variables. These values guide the managers of the water resources system in decision taking since it provides definite information about the system. The authenticity of the results may be tested with previous data and performance of the system. The evaluation of the results is based on observations of actual performance; independent data are not used in the estimation of the input parameters but representative data collected over a wide range of operating conditions (Agunwamba, 2001).

\section{- Implementation of Result}

The aim of the entire process is to improve the system; this therefore suggests that if the decision were not implemented, the time and other resources committed in the process becomes an effort in futility. The decisions derived from the process must be implemented and properly galvanized with the expertise of the manager. Staff must be trained in the implementation of the new system, and positioned to possess adequate skills to execute the solution and ensure a smooth transition from the old to the new system. The performance of the new system must be monitored periodically until the new system is perfected. For the fact that the system environment is dynamic, sensitivity analysis needs to be carried out to determine the limits and boundaries under which the input parameter can produce optimal results (Agunwamba 2001).

\subsection{Optimization}

The term optimization is a mathematical process of determining the maximum and minimum values of a given linear progranmming model subject to a number of given constraints with non-negativity conditions. In mathematics, computer, science, engineering and management, it is the selection of a best element with regard to some criteria from a set of available alternatives. More generally, optimization includes finding best available values of the objective function given a defined boundary.

Optimization may involve integer programming, quadratic programming, fractional programming, stochastic programming, dynamic programming etc. Integer programming involves all LP problems in which some or all variables are constrained to be integer values while quadratic programming allows the objective function to have quadratic terms with the feasible set specified in equalities and inequalities. Fractional programming is an optimization of ratios of two non-linear functions while some of the constraints or parameters depend on random variables. Dynamic programming involves situations where the optimization strategy is to split the problem into sub-problem and the equation of the sub-problem is called bellman equation. There are some computer based softwares which can be applied in solving LP problems in less time. These softwares often called optimization solvers are used in facilitating the solution of LP models and other forms of optimization problems. Examples of some include TORA, LINDO, QSB etc (Sharma, 2009).

\section{APPLiCATIONS}

Linear programming is applied in all fields of human endeavor that require solution of quantitative problems often encountered in such disciplines as engineering, physics, biology, management, 
economics etc. LP is specifically recognized in its high potency in solving problems which involve allocation of scarce resources of which water is the chief due to its prime position of being one of the three essentials of life. Apart from its unique role in the allocation of scarce resources, LP can be applied in such areas of robotics (artificial intelligence), analysis, detection of planetary system in astronomy, population dynamics, spread of infectious diseases (AIDs) in biology, planning of production units in Chemical Engineering, waste disposal in cities, power supply network optimization in Electrical Engineering, prediction of oil or ore deposits and earthquake in Geosciences, stability of structures and structural optimization in Civil Engineering etc (Agunwamba, 2007). LP can also be applied in the use of materials, transportation engineering, industries, nutrition and dietetics.

\section{Methods of Solving LP PROBLEMS}

Linear programming problems are solved through the followings:

(a) Graphical Method

(b) Simplex Method

(c) Computer based Method

\section{(a) Graphical Method}

The graphical approach is limited to those cases in which either the number of rows or the number of columns is two or less. Hence the graphical method cannot be used for models that have three or more variables. The graphical method is therefore not an efficient method of solving real-life linear programming problems. The value of the graphical approach lies in its ability to show, without the benefit of a rigorous mathematical proof, several different characteristics of linear programming problems and their solutions. The graphical method consists of graphing the structural constraints and thereby determining the region of feasible solution. The graphical method of solving linear programming problems is prosecuted under two approaches namely;

(i) Corner Point Approach

(i) Iso-profit or Iso-Cost Approach.

\section{(i) Corner Point Approach}

The corner point is an approach that chooses its solutions through the analysis of coordinates of the vertices of the feasible region and can be carried out through these steps:

1. Convert the inequations of the constraints to equations for instance the inequation, $x+7 y \leq 5$ can be converted to equation $\mathrm{x}+7 \mathrm{y}=5$.

2. Assign $x=0$ and $y=0$ in each of the constraint equations to obtain two points for the drawing of graph for each constraint equation. For example, a constrain equation $x+7 y=5$ will have two points obtained thus;

When $\mathrm{x}=0, \mathrm{y}=5 / 7$ and $\mathrm{y}=0, \mathrm{x}=5$ and the two points for the constraint equations becomes $(0,5 / 7)$ and $(5,0)$.

3. Draw the graphs of the constraint equations and observe the plane of exclusion from the feasible region. Note whether the half plane of the graph chosen is near the origin or not, by observing if the substitution of $\mathrm{x}$ and $\mathrm{y}$ by zero $(\mathrm{x}=0$ and $\mathrm{y}=0)$ in the equation satisfies the inequation. If the inequation is satisfied the feasible region is near the origin $(0,0)$ but if not, it is on the other half of the plane. For instance, substituting $\mathrm{x}=0$ and $\mathrm{y}=0$ in $\mathrm{x}+7 \mathrm{y} \leq 5$ we have $0+0 \leq 5$ and the inequation is satisfied and therefore the feasible region is on the half plane near the origin.

4. All the domain or area satisfying the inequality constitutes the feasible region.

5. The extreme points or vertices (i.e. corner points) outlined by the feasible domain are solutions of the linear programming problem.

6. Analyse the extreme points by substituting their coordinates in the objective function to obtain the maximum or minimum values of the objective function as the case may be. 


\section{Worked Examples}

Example 1: A cottage hydro-based manufacturing company which produces two volume brands of 1 litre and 2 litres of table water with market outlets in three cities of Owerri, Warri and Benin is conducting a test run of its intended production capacity. At the Owerri market outlet the ratio of sales of 1 litre to 2 litre brands was reported to be $3: 4$ and the total sales has be exceeding 8 , the Warri and Benin had a ratio sales of 1:4 and 3:2 without the sales exceeding 16 and 18 respectively.

(i) Formulate the linear programme of the process.

(ii) Optimize the production capacity by determining the maximum production (apply the Corner Point Approach).

\section{Solution}

(i) The objective function will be to maximize the two volume brands of 1 litre and 2 litre of the table water and it can be stated thus; Let the decision variables of $1 \mathrm{~L}$ and $2 \mathrm{~L}$ capacities be denoted by $x$ and $y$ respectively. Therefore the objective function can be stated as $P=x+2 y$. The objective of the company can optimized through maximization.

Maximize $\mathrm{P}=\mathrm{x}+2 \mathrm{y}$ and the production will be subject to these limits which serve as constraints.

$3 \mathrm{x}+4 \mathrm{y} \geq 8$

$\mathrm{X}+4 \mathrm{y} \leq 16$

$3 \mathrm{x}+2 \mathrm{y} \leq 18$

And the non-negativity condition of $\mathrm{x}, \mathrm{y} \geq 0$ applies.

(ii). $\operatorname{Max} P=x+2 y$

Subject to constraint $3 x+4 y=8$

$$
\begin{gathered}
x+4 y=16 \\
3 x+2 y 18
\end{gathered}
$$

Converting all the in equations to equations:

$3 x+47 \geq 8$

$X+4 y \geq 16$

$3 \mathrm{x}+2 \mathrm{y} \leq 18$

Determining the co-ordinates of the constraint equations for the plotting of graph; For equation $3 \mathrm{x}+$ $4 \mathrm{y}=8$, when $\mathrm{x}=0, \Rightarrow \mathrm{y}=2$ and when $\mathrm{y}=\mathrm{o}, \mathrm{x}=8 / 3$. The co-ordinate points become $\mathrm{A}(0,2)$ and $\mathrm{B}$ $(8 / 3,0)$.

Assuming that $\mathrm{x}=0$ and $\mathrm{y}=0$, then $3 \mathrm{x}+4 \mathrm{y} \geq 8$ becomes $0+0 \geq 8$ and this is false and therefore the half plane lies not near the origin $(0,0)$.

For equation $\mathrm{x}+4 \mathrm{y}=16$, when $\mathrm{x}=0, \mathrm{y}=4$ and when $\mathrm{y}=0, \mathrm{x}=16$ and the co-ordinate points become $\mathrm{C}(0,4)$ and $\mathrm{D}(16,0)$.

Substituting $\mathrm{x}=0$ and $\mathrm{y}=0$ in the inequation $\mathrm{x}+4 \mathrm{y} \leq 16$ we have $0+0 \leq 16$ which is true and therefore the half plane lies near the origin $(0,0)$.

For equation $3 x+2 y=18$, when $x=0, y=9$ and when $y=0, x=6$ and the points are $E(0,9)$ and $F$ $(6,0)$. Substituting $\mathrm{x}=0$ and $\mathrm{y}=0$, we have $0+0 \leq 18$ which is true and therefore the half plane lies near the origin.

Plotting the graphs as analysed above: 


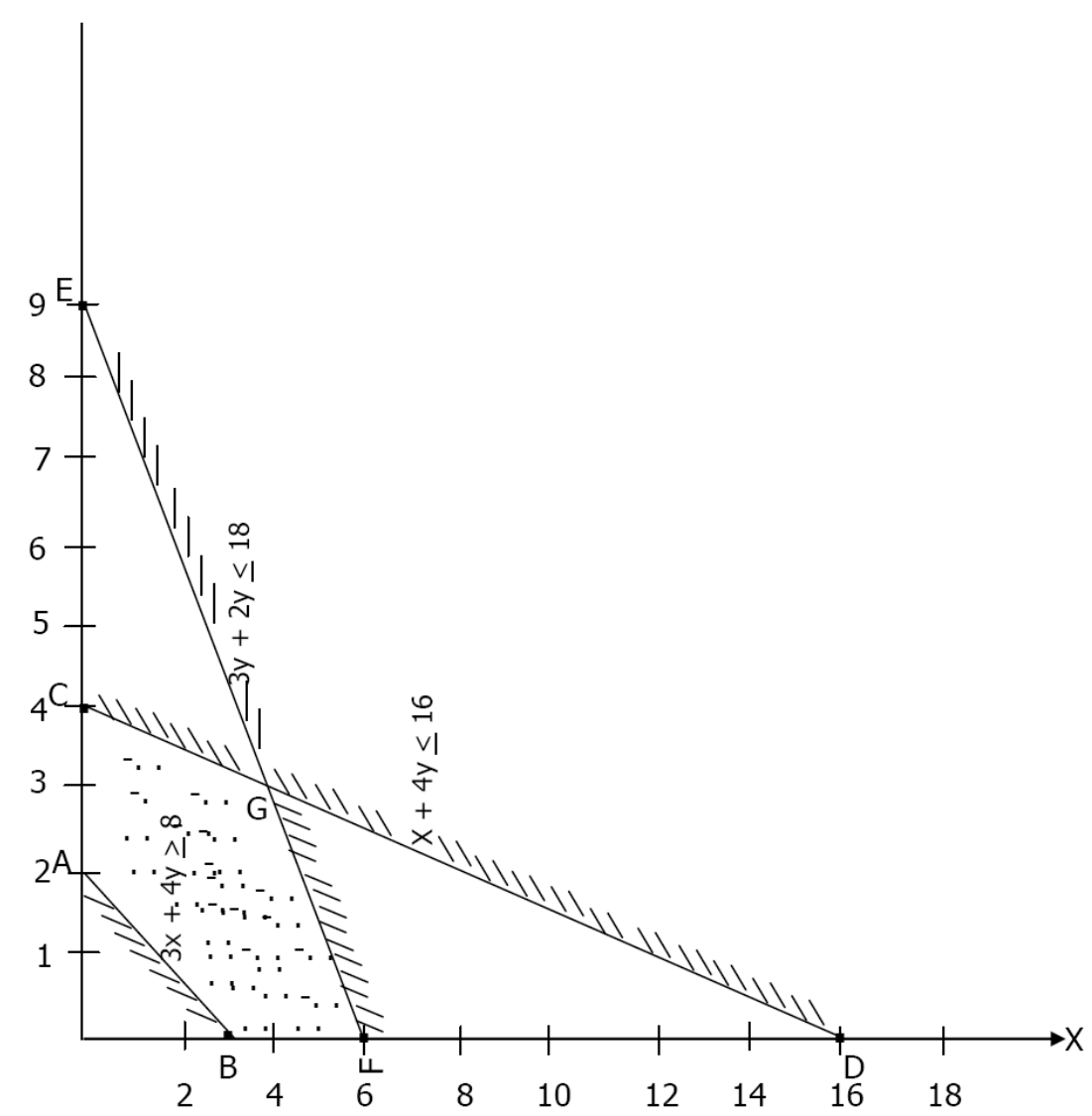

The area ABFGCA serves as the feasible domain and the five points are all feasible solutions.

Analyzing these points to obtain the maximum points by substituting the co-ordinates in the objective function.

\begin{tabular}{|c|c|}
\hline $\begin{array}{c}\text { Corner Points }(\mathrm{x}, \mathrm{y}) \text { of the feasible region } \\
\text { ABFGCA }\end{array}$ & $\begin{array}{c}\text { Value of objective function, } \\
\mathrm{P}=\mathrm{x}+2 \mathrm{y}\end{array}$ \\
\hline $\mathrm{A}(0,2)$ & $0+2 \times 2=4$ \\
\hline $\mathrm{B}(2.67,0$ & $2.67+2 \times 0=2.67$ \\
\hline $\mathrm{F}(6,0)$ & $6+2 \times 0=6$ \\
\hline $\mathrm{G}(4,3)$ & $4+2 \times 3=10$ \\
\hline $\mathrm{C}(0,4)$ & $0+2 \times 4=8$ \\
\hline
\end{tabular}

From the above, it can be observed that maximum point is at point $\mathrm{G}$ with the value of 10 .

It then means that the company maximum production should be pegged at 10 comprising of 4 units of the I-litre brand and 6 units of 2- litre brand.

\section{(b) Iso-profit or Iso-Cost Approach}

In the Iso-profit or Iso-cost approach, the graphs of the constraint equations are plotted as in corner point approach and the objective function is assigned a value that enables its graph to be plotted within the feasible region. Parallel graphs of the objective function is simulated at the edges to obtain the maximum. The steps of this approach for maximum point include:

\section{Follow the steps $1-3$ in the Corner Point Approach}

2. Assign a value to the objective function to enable co-ordinates be obtained for the plotting of its graph and let it be within the feasible region or domain and the graph drawn is called Iso-profit or isocost line.

3. Draw lines parallel with the graph of the objective function and let it pass through the edge of the feasible region.

4. The point of intersection of the parallel line with the feasible edge determines the maximum point.

The approach for the minimum point is the same except that series of parallel lines are drawn and the one that passes through the edge of the feasible region nearest to the origin is adopted. 


\section{Example 2}

A municipal water system which distributes water through the gravitation method suffers inadequate pressure in her distribution system. Research conducted revealed that the inadequacy in pressure could be remedied by introducing mechanical booster pumping stations at the various housing estates of the municipality. The pressures expected by the gravitation method and the mechanical pumping station in the entire municipality were put at $2 \mathrm{KN} / \mathrm{m}^{2}$ and $8 \mathrm{KN} / \mathrm{m}^{2}$ respectively. The municipality has three housing estates A, B and C. Housing Estate A is expected to have combined pressure of not more than $24 \mathrm{KN} / \mathrm{m}^{2}$, Housing Estate B should have a pressure of not more than $132 \mathrm{KN} / \mathrm{m}^{2}$ and Housing Estate $C$ will have a pressure of magnitude not less than $12 \mathrm{KN} / \mathrm{m}^{2}$. The pressure combinations for the Housing Estates are shown in table below.

\begin{tabular}{|c|c|c|c|}
\hline \multirow{2}{*}{ S/N } & Housing Estate & \multicolumn{2}{|c|}{ Pressures $\left(\mathrm{KN} / \mathrm{m}^{2}\right)$} \\
\cline { 3 - 4 } & & Gravitational Method & Mechanical Booster State \\
\hline 1. & A & 1.0 & 2.0 \\
\hline 2. & B & 7.0 & 6.0 \\
\hline 3. & C & 1.0 & 2.0 \\
\hline
\end{tabular}

(a) From the above, formulate;

(i) Objective function

(ii) Constraints Assume non-negativity conditions.

(b) Minimize the linear programming problem, hence determine the minimum pressure required in the municipality.

\section{Solution}

(a) From the question, the following formulations can be made:

(i) Objective function is

$\mathrm{Q}=2 \mathrm{x}_{1}+8 \mathrm{x}_{2}$

(ii)

$$
\begin{array}{ll}
\mathrm{x}_{1}+2 \mathrm{x}_{2} \leq 24 & \text { (Housing Estate A) } \\
7 \mathrm{x}_{1}+6 \mathrm{x}_{2} \leq 132 & \text { (Housing Estate B) } \\
\mathrm{x}_{1}+2 \mathrm{x}_{2} \geq 12 & \text { (Housing Estate C) }
\end{array}
$$

(iii) Non-negativity condition.

$\mathrm{x}_{1}, \mathrm{x}_{2}, \geq 0$

(b) Optimization Converting the inequations to equations

$$
\begin{aligned}
& x_{1}+2 x_{2}=24 \\
& 7 x_{1}+6 x_{2}=132 \\
& x_{1}+2 x_{2}=12
\end{aligned}
$$

Determining the co-ordinate points

For $\mathrm{x}_{1}+2 \mathrm{x}_{2}=24$, when $\mathrm{x}_{1}=0, \mathrm{x}_{2}=12$ and when $\mathrm{x}_{2}=0, \mathrm{x}_{1}=24$. The equation is plotted with the points $S(0,12)$ and $T(24,0)$, substituting $x_{1}=0$ and $x_{2}=0$ in $x_{1}+2 x_{2} \geq 24$ have $0+0 \geq 24$ this is false and therefore the half plane is away from the origin $(0,0)$.

For $7 \mathrm{x}_{1}+6 \mathrm{x}_{2}=132$, when $\mathrm{x}_{1}=0, \mathrm{x}_{2}=22$, and when $\mathrm{x}_{2}=0, \mathrm{x}_{1}=18.86$, and this result to two points of $\mathrm{U}(0,22)$ and $\mathrm{V}(18.86,0)$ which will be use to plot the graph. Substituting $\mathrm{x}_{1}=0$ and $\mathrm{x}_{2}=0$ in the inequation $7 \mathrm{x}_{1}+6 \mathrm{x}_{2} \leq 132$, we have $0+0 \leq 132$ which is true and therefore the half plane is near from the origin $(0,0)$.

For $\mathrm{x}_{1}+2 \mathrm{x}_{2}=12$, when $\mathrm{x}_{1}=0, \mathrm{x}_{2}=6$, and when $\mathrm{x}_{2}=0, \mathrm{x}_{1}=12$ and the equation can be plotted with the points $Y(0,6)$ and $Z(12,0)$. Substituting $x_{1}=0$ and $x_{2}=0$ in the inequation; $X_{1}+2 X_{2} \geq 12$, we have $0+0 \geq 12$ which is not true and the half plane lies away from the origin $(0,0)$. The graphs are plotted as shown below: 


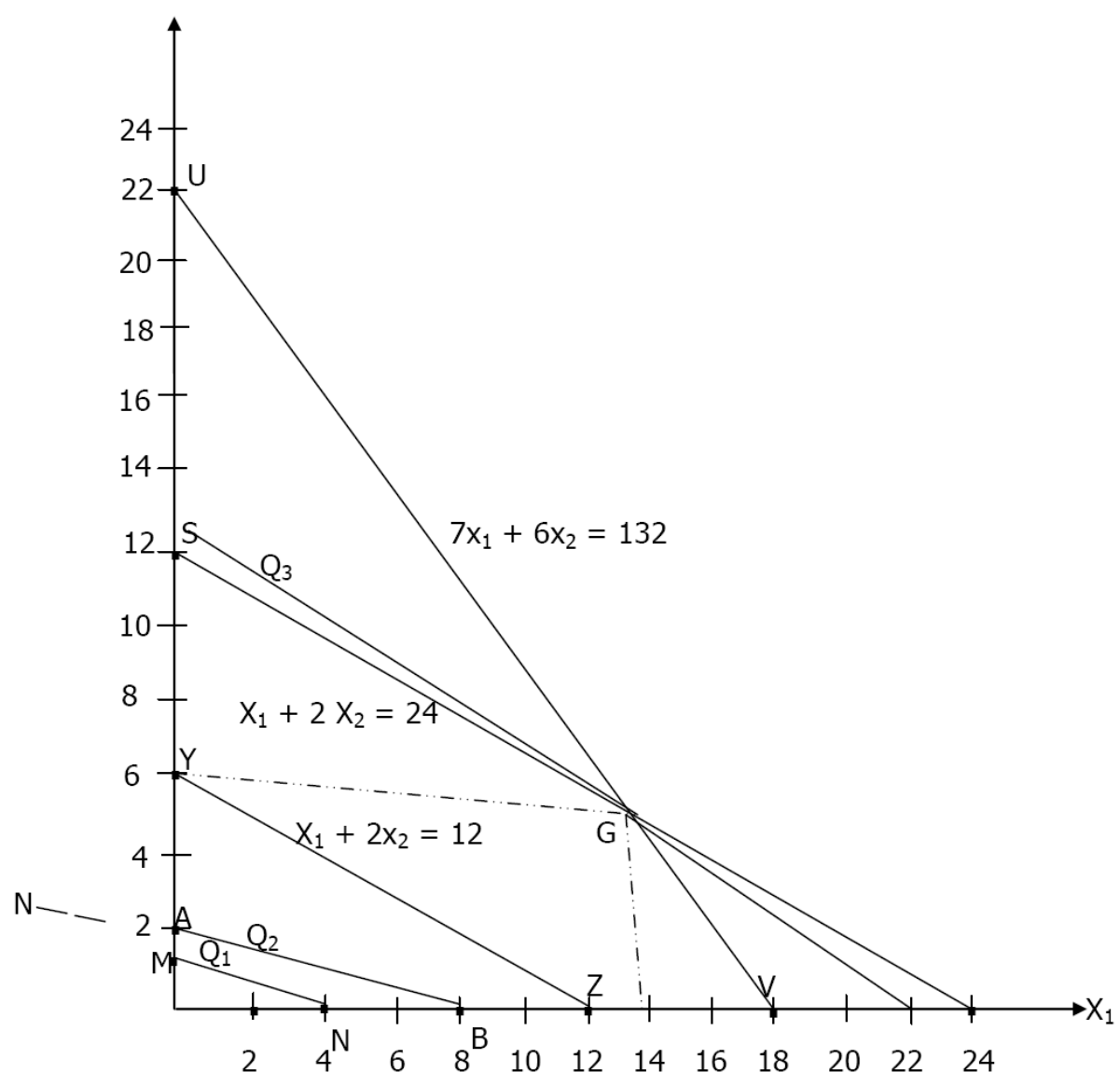

The objective function is $\mathrm{Q}=2 \mathrm{x}_{1}+8 \mathrm{x}_{2}$.

Putting a value for the objective function by assuming that the objective function $\mathrm{Q}_{1}=8$, we have $2 \mathrm{x}_{1}$ $+8 \mathrm{x}_{2}=8$. When $\mathrm{x}_{1}=0, \mathrm{x}_{2}=1$, and when $\mathrm{x}_{2},=0, \mathrm{x}_{1}=4$ and this results to two points $\mathrm{M}(0,1)$ and $\mathrm{N}$ $(4,0)$. This is plotted as the iso-profit or iso-cost line. Another value is assigned to $\mathrm{Q}_{2}$ as 16 and this enables another line parallel to the Iso-profit or iso cost line be drawn. With $2 x_{1}+8 x_{2}=16$, when $x_{1}=$ $0, x_{2}=2$ and when $x_{2}=0, x_{1}=8$ and this results to two points $A(0,2)$ and $B(8,0)$ which is used to plot a line parallel to the iso-profit or iso-cost line. Further lines parallel to iso-profit or iso-cost line was drawn and it meets the edge of the feasible region at $\mathrm{G}$ which is the minimum point. The point $\mathrm{G}$ has its co-ordinates as 14 and 6 . This implies that the optimal points (minimum) lies at $\mathrm{X}_{1}=14$ and $\mathrm{X}_{2}$ $=6$. The minimum pressure required in the municipality is stated as; $Q=2 x_{1}+8 x_{2}=2 x_{14}+8 \times 6=$ $76 \mathrm{KN} / \mathrm{m}_{2}$

\section{(b) Simplex Method}

Most LP problems when formulated have more than two variables and they are difficult to be interpreted with the help of the graphical solution method. Following this difficulty, the Simplex method was developed by G.B. Dantzing in 1947. The LP model was specifically developed primarily to military logistics problems. Its application has now been extended to functional areas of management, engineering, airlines, agriculture, military operations, oil refining, education, energy planning, The simplex method is one of the most general and powerful methods of solving linear programming problems. The simplex method rests on two concepts; feasibility and optimality.

The search for the optimal solution starts with a basic feasible solution or program. We look out for only the extreme-point solutions. The solution is tested for optimality and if it is not optimal, the search is stopped. If the test of optimality shows that the current solution is not optimal, a new and better feasible solution is designed. The feasibility of the new solution is guaranteed by the mechanics of the simplex method as it is a fact that each successive solution is achieved only if it is better than each of the previous solutions. This iterative process is continued until an optimal solution has been attained. There are two Simple method approaches which can be applied in solving LP problems namely: 
(1) Approach I

(2) Approach II

\section{Approach 1}

In this approach the simplex method is applied in solving LP problems by following these steps.

(i) Transform all in equations into equations through the introduction of the slack variables in case of maximization and including the addition of artificial variables in case of minimization.

(ii) Build the initial tableau with the data and information from the objective function and the constraints and determine the $\mathrm{Zj}$ and $\mathrm{Cj}-\mathrm{Zj}$ row values where $\mathrm{Cj}$ is the coefficient of the basic variable and $\mathrm{Zj}$ is the summation of the products of the $\mathrm{Cj}$ and the quantity i.e. $\mathrm{Zj}=\mathrm{Cj}$ x quantity.

(iii) Select the column with the highest positive value in the $\mathrm{Cj}-\mathrm{Zj}$ row in case of maximization or $\mathrm{Zj}$ $-\mathrm{Cj}$ in case of minimization and this column bearing the value is called pivot column.

(iv).Divide the quantity column values by corresponding pivot column values and select the row with the minimum non-negative quotient and the row is called pivot row.

(v) The value at the point of intersection between the pivot column and pivot row is called pivot element or number.

(vi) Develop a new tableau by entering as the first values the result obtained from dividing old tableau pivot row value by pivot number.

New tableau pivot row value $=\underline{\text { Old tableau pivot row value }}$

\section{Pivot element}

(vii) All the other row values of the new tableau are calculated by the formula.

New tableau $=$ Old row value - Corresponding value in pivot column of old table multiplied by Corresponding New tableau pivot row value

(viii) Determine the $\mathrm{Zj}$ and $\mathrm{Cj}-\mathrm{Zj}$ in case of maximization or $\mathrm{Zj}-\mathrm{Cj}$ for minimization.

(ix) Check if the optimal solution has been obtained. The optimal solution is attained when all the values in the $\mathrm{Cj}-\mathrm{Zj}$ row (for maximization) or $\mathrm{Zj}-\mathrm{Cj}$ row (for minimization) are zero and negative. If the condition is otherwise or not achieved, further iterations are undertaken.

\section{Example 3}

In Njaba river basin, the available water was allocated for the purposes of consumption, irrigation and electric power supply among three communities. The water allocated per annum per capita for all uses in these communities are $10 \mathrm{~m}^{3}, 10 \mathrm{~m}^{3}$ and $30 \mathrm{~m}^{3}$. The allocations were made based on the critical factors of population, land area and the industrialization. The populations of the communities are 300 , 200 , and 100 , power supply capacities are $20 \mathrm{~W}, 10 \mathrm{~W}$ and $20 \mathrm{~W}$ while the land areas for irrigation are 50 hectares, 40 hectares and 30 hectares respectively. Allowable allocations limits of more than 300 , 100 and 80 were stipulated for the purposes. Using the above information, formulate,

(a) Linear Programming Model for the basin.

(b) Maximization the allocations made

Assume non-negativity condition.

\section{Solution}

a. From the data and information given in the question;

Let the three communities be denoted by the variables $\mathrm{x}, \mathrm{y}$ and $\mathrm{z}$.

The objective function should be based on the allocation per annum, per capita for the basin as stated;

$\mathrm{Z}=10 \mathrm{x}+10 \mathrm{y}+30 \mathrm{z}$

The constraints can be formulated thus;

$300 x+200 y+100 z \geq 300$

$20 \mathrm{x}+10 \mathrm{y}+20 \mathrm{z} \geq 100$ 
$50 \mathrm{x}+40 \mathrm{y}+30 \mathrm{z} \geq 80$

Under the negativity conditions of

$\mathrm{X}, \mathrm{Y}, \mathrm{Z} \geq 0$.

b. Transforming all inequations into equations and adding the slack variables;

Objective function $Z=10 x+10 y+30 z+0 S_{1}+0 S_{2}+0 S_{3}$

Constraints: $300 x+200 y+100 z+S_{1} \geq 3000$

$20 \mathrm{x}+10 \mathrm{y}+20 \mathrm{z}+\mathrm{S}_{2} \geq 100$

$50 \mathrm{x}+40 \mathrm{y}+30 \mathrm{z}+\mathrm{S}_{3} \geq 80$

Initial Tableau

\begin{tabular}{|c|c|c|c|c|c|c|c|c|}
\hline \multirow[t]{2}{*}{$\mathrm{Cj}$} & \multirow[b]{2}{*}{ BV } & \multirow[b]{2}{*}{$\mathrm{Q}$} & 10 & 10 & 30 & 0 & 0 & 0 \\
\hline & & & $X$ & $\mathrm{Y}$ & $\mathrm{Z}$ & $S_{1}$ & $S_{2}$ & $S_{3}$ \\
\hline 0 & $S_{1}$ & 300 & 300 & 200 & 100 & 1 & 0 & 0 \\
\hline 0 & $\mathrm{~S}_{2}$ & 100 & 20 & 10 & 20 & 0 & 1 & 0 \\
\hline 0 & $\mathrm{~S}_{3}$ & 80 & 50 & 40 & 30 & 0 & 0 & 1 \\
\hline & $\mathrm{Zj}$ & & 0 & 0 & 0 & 0 & 0 & 0 \\
\hline & $\mathrm{Cj}-\mathrm{Zj}$ & & 10 & 10 & 30 & 0 & 0 & 0 \\
\hline
\end{tabular}

$\mathrm{Zj}=\Sigma(\mathrm{Cj} * \mathrm{Q})$

$=\quad 300 \times 0+20 \times 0+50 \times 0=0$

$=200 \times 0+10 \times 0+40 \times 0=0$

$=\quad 100 \times 0+20 \times 0+30 \times 0=0$

$=\quad 1 \times 0+0 \times 0+0 \times 0=0$

$=\quad 0 \times 0+1 \times 0+0 \times 0=0$

$=\quad 0 \times 0+0 \times 0+0 \times 1=0$

$\mathrm{Cj}-\mathrm{Zj}=10-0=10,10-0$,

$$
\begin{aligned}
& 30-0=0,0-0=0,0-0=0 \\
& 0-0=0
\end{aligned}
$$

The column that has the highest positive value in the $\mathrm{Cj}-\mathrm{Zj}$ row is the $6^{\text {th }}$ column and it is the pivot column.

Dividing the quantities by the corresponding pivot column values.

$\underline{300}=3, \underline{100}=5, \underline{80}=2.67$

$100 \quad 20 \quad 30$

From the figures, the quotient 2.67 is the minimum non-negative value and it belongs to $4^{\text {th }}$ row. The $4^{\text {th }}$ row becomes the pivot row.

The point of intersection between the pivot column and pivot row is 30 and it becomes the pivot element.

Developing the new tableau, we have $2^{\text {nd }}$ Tableau

\begin{tabular}{|c|c|c|c|c|c|c|c|c|}
\hline $\mathrm{Cj}$ & & 10 & 10 & 30 & 0 & 0 & 0 \\
\cline { 4 - 9 } & $\mathrm{BV}$ & $\mathrm{Q}$ & $\mathrm{X}$ & $\mathrm{Y}$ & $\mathrm{Z}$ & $\mathrm{S}_{1}$ & $\mathrm{~S}_{2}$ & $\mathrm{~S}_{3}$ \\
\hline 0 & $\mathrm{~S}_{1}$ & 33 & 133 & 67 & 100 & 1 & 0 & -3 \\
\hline 0 & $\mathrm{~S}_{2}$ & 46.6 & -13.4 & -16.6 & 20 & 0 & 1 & -0.6 \\
\hline 0 & $\mathrm{~S}_{3}$ & 2.67 & 1.67 & 1.33 & 0 & 0 & 0 & 0.03 \\
\hline & $\mathrm{Zj}$ & & 0 & 0 & 0 & 0 & 0 & 0 \\
\hline & $\mathrm{Cj}-\mathrm{Zj}$ & 10 & 10 & 30 & 0 & 0 & 0 \\
\hline
\end{tabular}


New Value = Old Value minus [Value in the corresponding pivot column in the old tableau] multiplied by [value in the new tableau]. The values in the rows of the $2^{\text {nd }}$ Tableau can be calculated thus;

$$
\begin{array}{ll}
= & 300-100 \times 2.67=33 \\
= & 300-100 \times 1.67=133 \\
= & 200-100 \times 1.33=67 \\
= & 100-100 \times 0=100 \\
= & 1-100 \times 0=1 \\
= & 0-100 \times 0=0 \\
= & 0-100 \times 0.03=-3 \\
= & 100-20 \times 2.67=46.6 \\
= & 20-20 \times 1.67=-13.4 \\
= & 10-20 \times 1.33-=16.6 \\
= & 20-20 \times 0=20 \\
= & 0-20 \times 0=0 \\
= & 1-20 \times 0=1 \\
= & 0-20 \times 0.03=-0.6 \\
\mathrm{Zj}=\Sigma(\mathrm{Cj} \times \mathrm{Q})
\end{array}
$$

The highest positive value in the $\mathrm{Cj}-\mathrm{Zj}$ row is 30 and it belongs to column 6 and that is the pivot column. Dividing the quantity by corresponding value in the pivot row,

$\underline{33}=0.33, \quad \underline{46.6}=2.33, \underline{2.67}=0$

$100 \quad 20 \quad 0$

The minimum positive quotient is 0.33 and therefore the $2^{\text {nd }}$ row becomes the pivot row while 100 is the pivot element.

Developing a new tableau by using the pivot element to divide the pivot row $3^{\text {rd }}$ Tableau

\begin{tabular}{|c|c|c|c|c|c|c|c|c|}
\hline $\mathrm{Cj}$ & & & 10 & 10 & 30 & 0 & 0 & 0 \\
\cline { 4 - 9 } & $\mathrm{BV}$ & $\mathrm{Q}$ & $\mathrm{X}$ & $\mathrm{Y}$ & $\mathrm{Z}$ & $\mathrm{S}_{1}$ & $\mathrm{~S}_{2}$ & $\mathrm{~S}_{3}$ \\
\hline 30 & $\mathrm{Z}$ & 0.33 & 1.33 & 0.67 & 1 & 0.01 & 0 & -0.03 \\
\hline 0 & $\mathrm{~S}_{2}$ & 40 & -40 & -30 & 0 & -0.2 & 1 & 0 \\
\hline 0 & $\mathrm{~S}_{3}$ & 2.67 & 1.67 & 1.33 & 0 & 0 & 0 & 0.03 \\
\hline & $\mathrm{Zj}$ & & 39.9 & 20.1 & 30 & 0.3 & 0 & -0.9 \\
\hline & $\mathrm{Cj}-\mathrm{Zj}$ & & -29.9 & -10.1 & 0 & -0.3 & 0 & 0.9 \\
\hline
\end{tabular}

New values:

$$
\begin{array}{ll}
= & 2.67-0 \times 0.33=2.67 \\
= & 1.67-0 \times 1.33=1.67 \text { etc } \\
= & 46.6-20 \times 0.33=40 \\
= & -13.4-20 \times 1.33=-40 \\
= & -16.6-20 \times 0.67=-30 \\
= & 20-20 \times 1=0 \\
= & 0-20 \times 0.01=-0.2 \\
= & 1-20 \times 0=1 \\
= & -0.6-20(-0.03)=0
\end{array}
$$


$\mathrm{Zj}=\Sigma(\mathrm{Cj} \times \mathrm{Q})$

Iterating further, the $9^{\text {th }}$ column is the highest positive number in the $\mathrm{Cj}-\mathrm{Zj}$ row.

Dividing the quantity by corresponding value in pivot column:

$$
\frac{0.33}{-0.03}=-11, \underline{40}=0, \underline{2.67}=89
$$

The pivot element is 0.03 and the $4^{\text {th }}$ row is the pivot row.

Developing a new tableau by dividing the pivot row values by the pivot element.

$4^{\text {th }}$ Tableau

\begin{tabular}{|c|c|c|c|c|c|c|c|c|}
\hline $\mathrm{Cj}$ & & & 10 & 10 & 30 & 0 & 0 & 0 \\
\cline { 4 - 9 } & $\mathrm{BV}$ & $\mathrm{Q}$ & $\mathrm{X}$ & $\mathrm{Y}$ & $\mathrm{Z}$ & $\mathrm{S}_{1}$ & $\mathrm{~S}_{2}$ & $\mathrm{~S}_{3}$ \\
\hline 30 & $\mathrm{Z}$ & 3 & 3 & 2.0 & 1 & 0.01 & 0 & 0 \\
\hline 10 & $\mathrm{Y}$ & 40 & -40 & -30 & 0 & 0.2 & 1 & 0 \\
\hline 0 & $\mathrm{~S}_{3}$ & 89 & 55.67 & 44.33 & 0 & 0 & 0 & 1 \\
\hline & $\mathrm{Zj}$ & & -310 & -240 & 30 & $2 / 3$ & 10 & 0 \\
\hline & $\mathrm{Cj}-\mathrm{Zj}$ & & 320 & 250 & 0 & -2.3 & -10 & 0 \\
\hline
\end{tabular}

Obtaining other new values:

$0.33-(-0.03)(89)=3$

$1.33-(-0.03)(55.57)=3.0$

$0.67-(-0.03)(44.33)=1.9999$

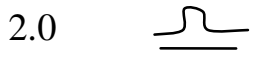

$1-(-0.03)(0)=1$

$0.01-(-0.03)(0)=0.01$

$-0.03-(-0.03)(1)=0$ etc

The highest positive value in the $\mathrm{Cj}-\mathrm{Zj}$ is in the $4^{\text {th }}$ column and therefore it is becomes the pivot column.

Dividing the quantity by corresponding values in pivot column

$3 / 3=1,40 /-40=-1,89 / 55.67=1.60$

Therefore the value 3 is the pivot element. Developing a new tableau.

$5^{\text {th }}$ Tableau

\begin{tabular}{|l|l|l|l|l|l|l|l|l|}
\hline $\mathrm{Cj}$ & & & 10 & 10 & 30 & 0 & 0 & 0 \\
\cline { 4 - 9 } & $\mathrm{BV}$ & $\mathrm{Q}$ & $\mathrm{X}$ & $\mathrm{Y}$ & $\mathrm{Z}$ & $\mathrm{S}_{1}$ & $\mathrm{~S}_{2}$ & $\mathrm{~S}_{3}$ \\
\hline 30 & $\mathrm{Z}$ & 1 & 1 & 0.67 & 0.33 & 0.003 & 0 & 0 \\
\hline 10 & $\mathrm{Y}$ & 80 & 0 & -3.2 & 13.2 & 0.32 & 1 & 0 \\
\hline 10 & $\mathrm{X}$ & 33.33 & 0 & 7.03 & -18.37 & -0.167 & 0 & 1 \\
\hline & $\mathrm{Zj}$ & & 30 & 58.4 & -41.8 & 1.62 & 10 & 10 \\
\hline & $\mathrm{Cj}-\mathrm{Zj}$ & & -20 & -48.4 & 71.8 & -1.62 & -10 & -10 \\
\hline
\end{tabular}

$89-(55.67)(1)=33.33$

$55.67-(55.67)(1)=0$

$44.33-(55.67)(0.67)=7.03$

$0-(55.67)(0.003)=$

$0-(55.67(0)=0$

$1-(55.67(0)=1$

$40-(-40)(1)=80$

$-40-(-40)(1)=0$

$-30-(-40)(0.67)=-3.2$

$0-(-40)(0.33)=13.2$ 
$0.2-(-40)(0.003)=0.32$

$1-(-40)(0)=0$ etc

$\mathrm{Zj} \quad=\quad 30 \times 1+10 \times 0+10 \times 0=30$

$=\quad 20.1-32+70.3=58.4$

$=9.9+131-183.7=-41.8$

$=\quad 0.09+3.2-1.67=1.62$

$=0+10+0=10$ etc

The sixth column is the pivot column and the second row is the pivot row with the value of 0.33 as the pivot element.

Developing a new tableau by dividing the second row by the pivot element.

$6^{\text {th }}$ Tableau

\begin{tabular}{|c|c|c|c|c|c|c|c|c|}
\hline $\mathrm{Cj}$ & & & 10 & 10 & 30 & 0 & 0 & 0 \\
\hline & $\mathrm{BV}$ & $\mathrm{Q}$ & $\mathrm{X}$ & $\mathrm{Y}$ & $\mathrm{Z}$ & $\mathrm{S}_{1}$ & $\mathrm{~S}_{2}$ & $\mathrm{~S}_{3}$ \\
\hline 30 & $\mathrm{Z}$ & 3.03 & 3.03 & 2.03 & 1 & 0.009 & 0 & 0 \\
\hline 10 & $\mathrm{Y}$ & 40 & -40 & -30 & 0 & 0.201 & 1 & 0 \\
\hline 10 & $\mathrm{X}$ & 88.99 & 55.66 & 44.32 & 0 & -0.002 & 0 & 1 \\
\hline & $\mathrm{Zj}$ & & 247.5 & 204.1 & 30 & 2.26 & 10 & 10 \\
\hline & $\mathrm{Cj}-\mathrm{Zj}$ & & -237.5 & -194.1 & 0 & -2.26 & -10 & -10 \\
\hline
\end{tabular}

$33.33-(-18.37)(3.03)=88.99$

$0-(-18.37)(3.03)=55.66$

$7.03-(-18.37)(2.03)=44.32$

$-18.37-(-18.37(1)=0$

$-0.167-(-18.37)(0.009)=-0.002$

$0-(-18.37)(0)=0 \quad$ etc

$80-(13.2)(3.03)=40.004$

$0-(13.2)(3.03)=-39.996$

$-3.2-(13.2)(2.03)=-30$

$13.2-(13.2)(1)=0$

$0.32-(13.2)(0.009)=0.20$

$1-13.2 \times 0=1 \quad$ etc

$\mathrm{Zj} \quad=\quad \Sigma(\mathrm{Cj} \times \mathrm{Q})$

$=90.9-400+556.6=247.5$

$=\quad 60.9-300+443.2=204.1$

$=30+0+0=30$

$=\quad 0.27+2.01-0.02=2.26$

From the sixth table, it can be observed that $\mathrm{Cj}-\mathrm{Zj}$ row have values that are only zero and negative numbers and this shows that the optimal solution has been attained.

The solution of the LP problem shows that $\mathrm{X}=88.99$,

$\mathrm{Y}=40$ and $\mathrm{Z}=3.03$.

The maximized objective of the allocation can be obtained thus:

Maximum optimal allocation: $Z=(10 \times 88.99)+(10 \times 40)+(30 \times 3.03)=(889.9+400+90.9) \mathrm{m}^{3}=$ $1,380.8 \mathrm{~m}^{3}$ 
The solution above reveals that the number of iterations required to arrive at an optimal solution is twice the number of constraint equations. The linear programming, problem solved above has three constraint equations and the number of iterative tableau that resulted to the optimal solution is six in number.

(2) Approach II

Steps for the alternative approach II are stated below:

(1) Transform all inequalities into equations by adding the slack and artificial variables. Constraint inequalities with less than inequality sigh attracts the addition of slack variable. while inequalities with more than inequality sign attracts the subtraction of the slack variables and the addition of artificial variables at the same time.

(2) The objective function is transformed through the addition of artificial variables and equating the terms to zero.

(3) The above transformations are arranged in a tableau with objective function as the last row and serves as the index row.

(4) The highest negative value in the index row marks out the pivot column while the least nonnegative quotient obtained by dividing the quantity by the corresponding values in the pivot column determines the pivot row. The point of intersection of the pivot column and the pivot row serves as the pivot or key element.

(5) All other values are obtained as in the first approach 1.

(6) Unlike in the first approach A, optimal solutions are attained when there is no further negative value in the index row. It should be noted that optimal solutions cannot be said to have been attained when the artificial variables are still forming part of the solutions. Efforts should be made to eliminate the artificial variables so that they will not form part of the solution.

(7) The process for maximization and minimization is the same in this approach except that the objective function for minimization is transformed into its negative form for optimization. The relationship existing between the maximization and the minimization process can be put thus $\mathrm{Q}_{\min }=$ $\mathrm{Z}_{\max }$.

\section{Example 4}

In a catchment basin, the negative effects of entrophication in the two rivers known as Citrus and Green were assessed and translated into numerical quantities. The table below illustrates the adverse effects on three categories of water users $\mathrm{M}, \mathrm{N}$ and 0 .

\begin{tabular}{|l|l|l|l|}
\hline Water users & Effects of eutrophication & Allocable effects \\
\hline $\mathrm{M}$ & 3 & 4 & $\leq 80$ \\
\hline $\mathrm{N}$ & -3 & 4 & $\leq 8$ \\
\hline 0 & 1 & 4 & $\leq 40$ \\
\hline
\end{tabular}

The disease factor due to the eutrophication effects were put at -2 and 8 units. Using the information,

(i) Formulate LP problem

(ii) Undertake the minimization process of the problem

Solution

iLet the two rivers Citrus and Green river be denoted by the variables $\mathrm{X}$ and $\mathrm{Y}$. The objective function is the disease factor which is the ultimate effect of the entrophication. The objective function can be put as:

$\mathrm{Q}=-2 \mathrm{x}+8 \mathrm{y}$

The constraints can stated thus:

$3 \mathrm{x}+4 \mathrm{y} \leq 80$

$-3 \mathrm{x}+4 \mathrm{y} \geq 8$

$\mathrm{X}+4 \mathrm{y} \geq 40$ 
$\mathrm{X}, \mathrm{y} \geq 0$

ii $\operatorname{Min} \mathrm{Q}=-2 \mathrm{x}+8 \mathrm{y}$

Subject to: $\quad 3 x+4 y \leq 80$

$$
\begin{aligned}
& -3 x+4 y \geq 8 \\
& X+4 y \geq 40
\end{aligned}
$$

In view of that two constraints have more than inequality sign, artificial variables will be added to them. The constraints are therefore transformed thus;

$\begin{array}{lll}3 \mathrm{x}+4 \mathrm{y}+\mathrm{S}_{1} & = & 80 \\ -3 \mathrm{x}+4 \mathrm{y}-\mathrm{S}_{2}+\mathrm{S}_{4} & = & 8 \\ \mathrm{X}+4 \mathrm{y}-\mathrm{S}_{3}+\mathrm{S}_{5} & = & 40\end{array}$

But $\mathrm{Q}_{\min }=-\mathrm{Z}_{\max }$, therefore the objective function can be transformed as

$\mathrm{Q}_{\min }=-\mathrm{Z}_{\max }=2 \mathrm{x}-8 \mathrm{y}$

Integrating the artificial variables in the objective function to have a unit matrix formed and equating to zero

$\mathrm{Z}-2 \mathrm{x}+8 \mathrm{y}+\mathrm{MS}_{3}+\mathrm{MS}_{5}=0$

The tableau is therefore built thus;

Initial Tableau

\begin{tabular}{|c|c|c|c|c|c|c|c|c|c|}
\hline $\mathrm{BV}$ & $\mathrm{X}$ & $\mathrm{Y}$ & $\mathrm{S}_{1}$ & $\mathrm{~S}_{2}$ & $\mathrm{~S}_{3}$ & $\mathrm{~S}_{4}$ & $\mathrm{~S}_{5}$ & $\mathrm{Q}$ & Check \\
\hline $\mathrm{S}_{1}$ & 3 & 4 & 1 & 0 & 0 & 0 & 0 & 80 & 88 \\
\hline $\mathrm{S}_{4}$ & -3 & 4 & 0 & -1 & 0 & 1 & 0 & 8 & 9 \\
\hline $\mathrm{S}_{5}$ & 1 & 4 & 0 & 0 & -1 & 0 & 1 & 40 & 45 \\
\hline $\mathrm{Z}$ & -2 & 8 & 0 & 0 & 0 & $\mathrm{M}$ & $\mathrm{M}$ & 0 & $2 \mathrm{M}+6$ \\
\hline
\end{tabular}

In the above tableau, the unit matrix is formed by $S_{1}, S_{4}$ and $S_{5}$. The solution will commence by identifying the least negative value in the index row (i.e. $\mathrm{Z}$ row) which is -2 . Therefore the $\mathrm{x}$ column becomes the pivot column.

The pivot row is identified by dividing the quantity by the corresponding pivot column values and choosing the least or minimum non-negative quotient.

$\underline{88}=29.3, \underline{45}=45$

$3 \quad 1$

This means that the $S_{1}$ row is the pivot row and the pivot element is 3. Dividing the pivot row by the pivot element to form the first row values for the new tableau.

$2^{\text {nd }}$ Tableau

\begin{tabular}{|c|c|c|c|c|c|c|c|c|c|}
\hline $\mathrm{BV}$ & $\mathrm{X}$ & $\mathrm{Y}$ & $\mathrm{S}_{1}$ & $\mathrm{~S}_{2}$ & $\mathrm{~S}_{3}$ & $\mathrm{~S}_{4}$ & $\mathrm{~S}_{5}$ & $\mathrm{Q}$ & Check \\
\hline $\mathrm{S}_{1} \mathrm{X}$ & 1 & 1.33 & 0.33 & 0 & 0 & 0 & 0 & 26.7 & 29.36 \\
\hline $\mathrm{S}_{4}$ & 0 & 7.99 & 0.99 & -1 & 0 & 1 & 0 & 88.1 & 97.08 \\
\hline $\mathrm{S}_{5}$ & 0 & 2.67 & -0.33 & 0 & -1 & 0 & 1 & 13.3 & 15.67 \\
\hline $\mathrm{Z}$ & 0 & 10.66 & 0.66 & 0 & 0 & $\mathrm{M}$ & $\mathrm{M}$ & 53.4 & $2 \mathrm{M}+64.72$ \\
\hline
\end{tabular}

New values for $S_{5}$ row $=1-(1)(1)=0,4-(1)(1.33)=2.67$,

$0-(1)(0.33)=-0.33,0-(1)(0)=0,-1-(1)(0)=-1$

$0-(1)(0)=0,1-(1)(0)=1,40-(1) 26.7)=13.3$

For $\mathrm{S}_{4}$ row: $-3-(-3)(1)=0,4-(-3)(1.33)=7.99$

$$
0-(-3)(0.33)=0.99,-1-(-3)(0)=-1
$$

$0-(-3(0)=0,1-(-3)(0)=1,0-(-3)(0)=0$

$8-(3)(26.7)=88.1$, 
For $\mathrm{Z}$ row: $-2-(-2)(1)=0,8(-2)) 1.33)=10.66$

$$
0-(-2)(0.33)=0.66,0-(-2)(0)=0,0-(-2)(0)=0
$$

$\mathrm{M}-(-2)(0)=\mathrm{M}, \mathrm{M}-(-2)(0)=\mathrm{M}, 0-(-2)(26.7)=53.4$

In the above tableau, we have gotten rid of the artificial variable $S_{1}$ and it is replace by $X$. There is need to eliminate of the artificial variable $S_{4}$ and $S_{5}$ even though there is no negative entry in the index row (i.e. $\mathrm{Z}$ row). This is necessary because the artificial variable does not need to be a part of the solution. To do this, we target at reducing 2.67 value in $S_{5}$ row to unity by choosing it as the pivot element and this will help to form the new tableau:

$3^{\text {rd }}$ Tableau

\begin{tabular}{|c|c|c|c|c|c|c|c|c|c|}
\hline $\mathrm{BV}$ & $\mathrm{X}$ & $\mathrm{Y}$ & $\mathrm{S}_{1}$ & $\mathrm{~S}_{2}$ & $\mathrm{~S}_{3}$ & $\mathrm{~S}_{4}$ & $\mathrm{~S}_{5}$ & $\mathrm{Q}$ & Check \\
\hline $\mathrm{X}$ & 1 & 0 & 0.499 & 0 & 0.499 & 0 & -0.499 & 20.08 & 21.58 \\
\hline $\mathrm{S}_{4}$ & 0 & 0 & 2.0 & -1 & 2.99 & 1 & -3.0 & 48.3 & 50.3 \\
\hline $\mathrm{S}_{5}$ & 0 & 1 & -0.127 & 0 & -0.375 & 0 & 0.375 & 4.98 & 5.85 \\
$\mathrm{y}$ & & & & & & & & & $2 \mathrm{~m}+$ \\
\hline $\mathrm{Z}$ & 0 & 0 & 2.014 & 0 & 3.998 & $\mathrm{M}$ & $\mathrm{M}-3.998$ & 0.31 & 2.324 \\
\hline
\end{tabular}

New Values: $Z$ row: $0-(10.66)(0)=0$,

$10.66-(10.66)(1)=0,0.66-(10.66)(-0.127)=2.014$

$0-(10.66)(0)=0,0-(10.66)(-0.375)=3.998$

$\mathrm{M}-(10.66)(0)=\mathrm{M}, \mathrm{M}-(10.66)(0.375)=\mathrm{M}-3.998$

$53.4-(10.66)(4.98)=0.313$

For $\mathrm{X}$ row; $1-(1.33)(0)=1,1.33-(1.33)(1)=0$

$0.33-(1.33)(-0.127)=0.499,0-(1.33)(0)=0$,

$0-(1.33)(-0.375)=0.499,0-(1.33)(0)=0$

$0-(1.33)(0.375)=-0.499,26.7-(1.33)(4.98)=20.08$

For $\mathrm{S}_{4}$ row: $0-(7.99(0)=0,7.99-(7.99)(1)=0$

$0.99-(7.99)(-0.127)=2.0,-1-(7.99(0)=-1$

$0-(7.99)(-0.395)=2.99,1-(7.99(0)=1$

$0-(7.99)(0.375)=-3.0,88.1-(7.99)(4.98)=48.3$

From the $3^{\text {rd }}$ tableau, the artificial variable $S_{5}$ has been eliminated and replaced by variable $y$. Artificial variable $S_{4}$ still needs to be eliminated. Eliminating artificial variable $S_{4}$ will be better done by reducing value of 2 in the $S_{4}$ row to unity through the division of $S_{4}$ row by 2 . The new tableau therefore becomes.

$4^{\text {th }}$ Tableau

\begin{tabular}{|c|c|c|c|c|c|c|c|c|c|}
\hline $\mathrm{BV}$ & $\mathrm{X}$ & $\mathrm{Y}$ & $\mathrm{S}_{1}$ & $\mathrm{~S}_{2}$ & $\mathrm{~S}_{3}$ & $\mathrm{~S}_{4}$ & $\mathrm{~S}_{5}$ & $\mathrm{Q}$ & Check \\
\hline $\mathrm{X}$ & 1 & 0 & 0 & 0.25 & -0.25 & -0.25 & 0.25 & 8.00 & 9 \\
\hline$S_{4}$ & 0 & 0 & 1 & -0.5 & 1.50 & 0.5 & -1.5 & 24.2 & 25.2 \\
\hline $\mathrm{S}_{1}$ & & & & & & & & & \\
\hline $\mathrm{Y}$ & 0 & 1 & 0 & 0.064 & -0.18 & 0.064 & 0.18 & 8.05 & 9.05 \\
\hline $\mathrm{Z}$ & 0 & 0 & 0 & 1.007 & 0.977 & $\mathrm{M}-1.007$ & $\mathrm{M}-0.977$ & -48.43 & $2 \mathrm{~m}-$ \\
& & & & & & & & & 48.43 \\
\hline
\end{tabular}

New values: $X$ row: $1-(0.499)(0)=1,0-(0.499)(0)=0$

$0.499-(0.499)(1)=0,0-(0.499)(-0.5)=0.25$

$0.499-(0.499)(1.50)=-0.25,0-(0.499)(0.5)=-0.25$

$-0.499-(0.499)(-1.5) 0.25$,

$20.08-(0.499)(24.2)=8.00$

$\mathrm{y}$ row: $0-(-0.127)(0)=0,1-(-0.127)(0)=1$

$-0.127-(-0.127)(1)=0,0-(-0.127)(-0.5)=-0.064$ 
$0.375-(-0.127)(1.5)=-0.18,0-(-0.127)(0.5)=0.064$

$0.375-(-0.127)(-1.5)=0.18,4.98-(-0.127)(24.2)=8.05$

$\mathrm{Z}$ row: $0-(2.014)(0)=0,0-(2.014)(0)=0$,

$2.014-(2.014)(1)=0,0-(2.014)(-0.5)=1.007$

$3.998-(2.014)(1.5)=0.977, \mathrm{M}-(2.014)(0.5)=\mathrm{M}-1.007$,

$\mathrm{M}-3.998-(2.014)(-1.5)=\mathrm{M}-0.977$,

$0.31-(2.014)(24.2)=-48.43$

In the $4^{\text {th }}$ tableau, the artificial variable $S_{4}$ has been replaced by slack variable $S_{1}$.

From the final tableau (i.e. $4^{\text {th }}$ tableau), the results shows that $Z_{\max }=-48.43$, alternatively $-Z_{\max }=$ 48.43, but $\mathrm{Q}_{\min }=-\mathrm{Z}_{\max }=48.4$

$\therefore \mathrm{Q}_{\min }=48.4, \mathrm{X}=8, \mathrm{y}=8.05$.

C. Computer Based method

In the method, computer software is used to solve the LP problem. The coefficients of the variables in the objective function and constraints serve as input data which are fed into the computer and the results of the LP solution are displayed automatically. The method takes seconds of time to solve maze of LP models, it is less laborious and error-free. The software has the capacity to detect and assess the feasibility and optimality conditions of the LP problem. This method is very advantageous as it can be used to solve real life problems. The screen shot of the software solution in one of its iterative interface is shown below:

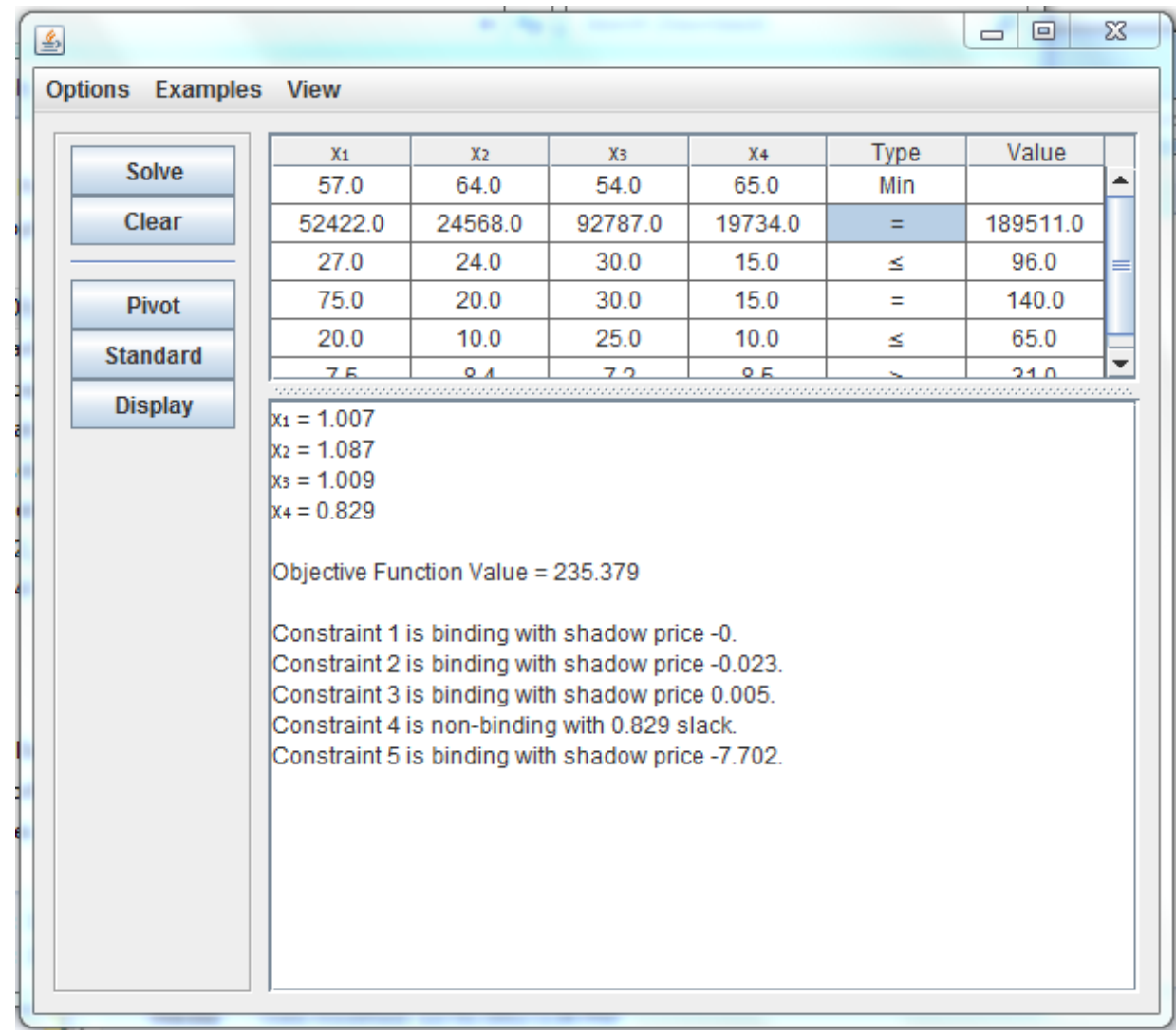

\section{CONCLUSION}

The work has thrown a great light on how linear programming can be applied in solving water resources based problems. It exposed the capacity and relevance of linear programming in tackling water related issues ranging from water resources optimization, pricing/marketing, allocations, water utilisation to conflict resolutions. Problems generated by communal crisis and clashes resulting from the riparian communities can easily be resolved through the collection of critical data about the communities and using them to form a linear programme for equitable distributions of water from the river basin. Linear programme plays immeasurable role in quantifications of water quality parameters and obtaining optimal values for water resources indices. 


\section{REFERENCES}

[1] Agunwawba J.C. (2007), Engineering Mathematical Analysis, Published De Adroil Innovations Publishers, Enugu, Pp. 503 - 507.

[2] Agunwamba J. C. (2001), Waste Engineering and Management Tools, Immaculate Publishes Ltd, Enugu. Pp. $501-572$

[3] Dass H.K. (2009), Advanced Engineering Mathematics, Published by S. Chand, New Delhi, Pp. 1243 1303.

[4] George, T. and Edward D.S. (2000) Water Quality Characteristics, Modeling, Modification, Published by Addison Wesley Publishing Company, Massachusetts, Pp. 560 - 577.

[5] Gupta, B.L. and Amid, Gupta (2010), Water Resources Systems and Management, Published by Standard Publishers, 1705-B, WaiSarak, Delhi-110006, P. 600 - 738.

[6] Obi L.E. (2013), Optimization Technique in Modeling Water Resources Allocation in Anambra - Imo River Basin, Unpublished Ph.D Thesis, Pp. 156 - 180.

[7] Obi L.E. (2011), Water Management : Veritable Approach To Water Supply Sustainability in Nigeria, International Journal of Engineering, India, Vol. 5, No. 1, pp.29-35

[8] Sharma J.K (2009), Operations Research, Theory and Applications, Macmillan Publishers Ltd India Pp. $16-40$.

[9] Sincero A.P. \& Sincero G.A. (1996), Environmental Engineering - A Design Approach, Published by Asoke K. Ghosh, New Delhi Pp. 99 - 230.

[10] Stroud K.A. (2003), Advanced Engineering Mathematics, $4^{\text {th }}$ Edition, Palgrave Macmillan, United Kingdom, Pp. 940 - 948.

\section{AUTHORS' BIOGRAPHY}

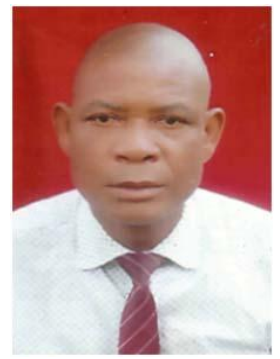

Engr. Dr. Obi Lawrence E., is a native of Ihioma in Orlu, Imo State Nigeria and he is a Senior Lecturer in the Department of Civil Engineering, Imo State University, Owerri. He holds a Ph.D in Civil Engineering from the renowned Federal University of Technology, Owerri, Imo State, Nigeria.

$\mathrm{He}$ is an experienced academic who has served as the Head of Civil Engineering Department and through his dint of hard work and mental prowess facilitated the accreditation of his department by Council for the Regulation of Engineering in Nigeria and the Nigerian Universities Commission. He is a chartered engineer and belongs to many professional bodies which include Nigerian Society of Engineers, Nigerian Institution of Civil Engineers, Nigerian Institution of Water Resources Engineering, Nigerian Renewable Energy Society, etc. He is a Fellow of the Institute of the Industrial Administration of Nigeria.

Engr. Dr .L.E. Obi has published extensively both in national and reputable international journals. $\mathrm{He}$ has earned such awards as the best H.O.D. Award for Civil Engineering, Eastern Merit Award for Excellence in Education, Distinguished Leadership Award, Golden General Secretary Award, etc Examples of his publications include-“ Mathematical Application of Simplex Numerical Method in the Allocation of Water in Aboine River Basin of Nigeria", European International Journal of Science and Technology, United Kingdom, Vol. 2 No 5, Pp. 173 - 190", "Development of Model Equations for the Allocation of Water Resources in Anambra Imo River Basin Development Authority of Nigeria, European International Journal of Applied Science and Technology, Kent, United Kingdom". $\mathrm{He}$ is currently the Chairman of International Conference in Engineering to be hosted by the Faculty of Engineering Imo State University, Owerri, Nigeria. His areas of interest in research include Optimization of Water Resources Engineering Systems, Modeling of Engineering Systems, Numerical Applications in Water Resources Development and Environmental Engineering.

Citation: Obi Lawrence E. (2017) Linear Programming as a Tool for Water Resources Management, International Journal of Constructive Research in Civil Engineering, 3(4), pp.30-47. DOI: http://dx.doi. org/10.20431/2454-8693.0304004

Copyright: (C) 2017 Obi Lawrence E.. This is an open-access article distributed under the terms of the Creative Commons Attribution License, which permits unrestricted use, distribution, and reproduction in any medium, provided the original author and source are credited. 